\title{
PERSPECTIVE
}

\section{Regeneration and transplantation of the optic nerve: developing a clinical strategy}

\author{
Robert E MacLaren
}

One of the major problems still confounding advances in modern ophthalmology is the seemingly irreversible and permanent nature of damage to the optic nerve. ${ }^{1}$ Severed axons of retinal ganglion cells, like the long tracts of the spinal cord, have no capacity for functional repair under normal physiological circumstances. This is most unfortunate, since a capacity for successful optic nerve regeneration is a necessity for restoration of vision following damage to the anterior visual pathway and might also open the door to future strategies of human whole eye transplantation. Influenced also by the tragic result of spinal cord transection, the topic of neuronal regeneration within the central nervous system (CNS) as a whole has become a most important area of medical research. Moreover, in the past few years, the extensive advances in neuroscience have made optic nerve (and spinal cord) regeneration a reality in laboratory mammals - either along existing pathways, ${ }^{23}$ through peripheral nerve bridges, ${ }^{45}$ from embryonic transplants, ${ }^{67}$ or at certain critical stages of CNS development. ${ }^{8-10}$ The significance and implications of these advances should be considered in relation to developing a future clinical strategy for optic nerve regeneration in humans.

In this review I shall discuss the various problems associated with optic nerve regeneration. There are certain structural differences between optic nerve and spinal cord pathways, but regeneration studies in both systems have so far correlated well. In either case, three key issues remain the same: (1) if a lesioned neuron can survive the effects of axotomy; (2) if the surviving neuron can regrow an axon through the CNS environment; and (3) if the regrowing axon can be guided back appropriately to its original target to reform patterned connections. As we shall see, the first two of these criteria have been successfully overcome in various experimental models of mammalian optic nerve regeneration, although the last question of axon guidance has not yet been fully addressed. In some non-mammalian vertebrates (for example, frogs and fish) optic nerve regeneration occurs naturally and regrowing axons are guided back to original targets. ${ }^{11}$ It might therefore be helpful to start this review by considering first some of the properties of successful optic nerve regeneration witnessed in these non-mammalian vertebrates.

\section{Optic nerve regeneration in lower vertebrates}

The protracted period of growth of the CNS during metamorphosis and adult maturation of some lower vertebrates provides an unusual CNS environment in which established and functioning axons need to co-exist with new and actively growing axons. ${ }^{12}$ In mammals, however, these events occur at different times. Development of the retinal projection is complete before eye opening and further axonal growth is not necessary within the functioning optic nerve. ${ }^{13}$ These developmental factors may therefore partly explain why optic nerve regeneration in frogs is so successful when compared with mammals. ${ }^{14}$ Of greater relevance perhaps, is that the successful optic nerve regeneration witnessed in lower vertebrates (after cessation of ganglion cell neurogenesis $)^{12}$ has provided us with an ideal model in which to investigate how the properties of axon navigation and retinal map formation might be replicated during regeneration.

In the adult stage, the optic nerve of the frog (Rana pipiens) projects predominantly to the contralateral optic tectum in a precise retinotopic order (Fig 1A). In the experiments performed by Sperry, ${ }^{11}{ }^{15}$ one eye was rotated through 180 degrees and the optic nerve was cut without disturbing the blood supply (Fig 1B). After a few weeks' delay to allow for regeneration, the contralateral optic nerve was cut to exclude inputs from the opposite eye, and a lure was presented in various quadrants of the visual field of the regenerated optic nerve. It was found that the frogs consistently aimed for the quadrant diametrically opposite the lure, and further lesions of the tectum confirmed that the regenerated retinotopic map had been completely inverted around the optical axis. ${ }^{11}$ This was an important result because it showed that the regeneration of retinotopic maps was not dependent upon how the cut optic nerve axons were surgically aligned, but was still determined by the retinal origin of the regenerating axons. Further experiments confirmed that individual regenerating ganglion cell axons retained an intrinsic ability to locate their appropriate central targets and reform retinotopic patterns, thus successfully replicating the normal events of development. ${ }^{16}$

Later experiments by Constantine-Paton and Law involved the transplantation of a third eye primordium into the forebrain region of a frog embryo (Fig 1C). The optic nerve of the transplanted eye innervated the nearest tectum where it too terminated in a retinotopic order. Since the innervated tectum was also developing connections from the normal contralateral optic nerve, some reorganisation took place such that sites were shared. This resulted in a form of ocular dominance column with alternating stripes of projection from either transplanted or contralateral eye (Fig 1C). ${ }^{17}$ The transplanted embryonic eye therefore had the capacity to interact with appropriate regions of a host tectum to form a retinotopic map. ${ }^{18}$

The frog experiments are therefore interesting models of optic nerve repair and provide information about two important aspects of retinal map formation. Firstly, it would seem that the re-establishment of a retinotopic map (which is most likely a requirement for functional recovery of vision) does not require a precise realignment of the two cut ends of the optic nerve. The retinotopic map is independently reformed by an interaction of regrowing 

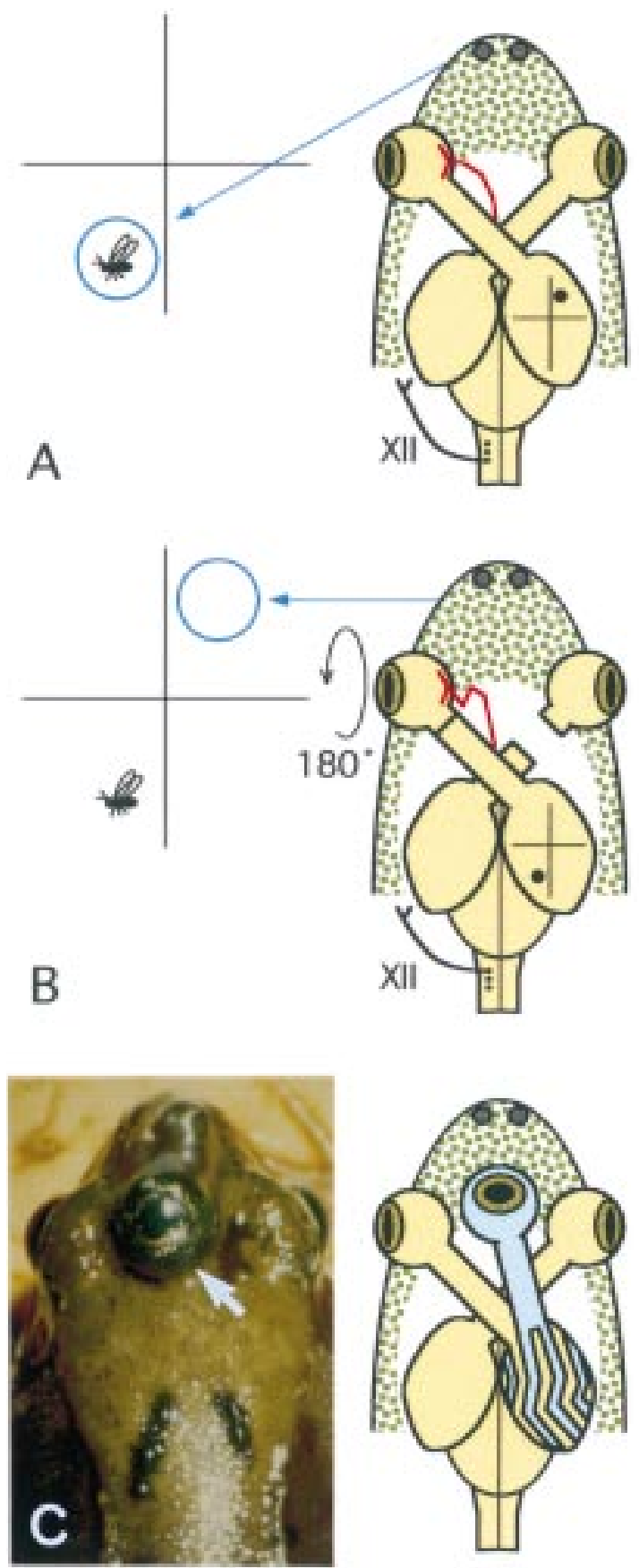

Figure 1 Optic nerve regeneration in the frog and the recreation of visual maps. (A) In normal circumstances, the left visual field maps precisely to the right optic tectum. Movement of a fly lure detected in the visual field will elicit a response at a corresponding location in the contralateral tectum. The tongue (blue arrow) will thus be directed appropriately towards the target. (B) If the left optic nerve is rotated about 180 degrees and cut (preserving the blood supply), following regeneration, an inverted map of visual space is reformed on the contralateral tectum. With the normal right optic nerve disconnected, the frog will perceive the lure to be in the opposite quadrant of visual space and will repeatedly miss the target with its tongue (blue arrow). This experiment therefore shows that regenerating ganglion cells in the frog retain an intrinsic ability to navigate back to appropriate central targets, despite complete misalignment of cut optic nerve fibres. Similar processes of axon pathfinding would most likely be necessary for successful optic nerve regeneration in primates. (C) A third eye

transplanted to the top of the head at embryonic stages can become fully functional (arrow). The transplanted eye (shown in blue) connects with correct retinal topography to the optic tectum, although tectal sites are shared with the host eye in an arrangement similar to ocular dominance columns (blue stripes). This observation suggests that guidance cues within a host tectum are also able to direct ganglion cells from a transplanted eye to appropriate targets. axons and guidance cues along the visual pathway. Secondly, the mechanisms that guide the formation of retinotopic projections are not restricted to host eyes, but can be equally effective in connecting transplanted eyes. Quite how these properties apply to optic nerve regeneration in mammals is unclear, and would depend on the extent to which developmental molecules remain or could be re-expressed along the visual pathway to guide regeneration. ${ }^{19}{ }^{20}$ An independent ability to reform retinotopic maps would be an important factor for successful mammalian optic nerve regeneration, since it is hard to imagine that accurate surgical realignment of individual nerve fibres would be possible, either within the optic nerve or in central targets. For this reason it is highly likely that successful optic nerve regeneration in mammals, as in lower vertebrates, would require some form of replication of the normal events of development. Before extending the discussion of map formation to the regenerating mammalian optic nerve, we should first consider the basic mechanisms of regeneration failure in the mammalian CNS.

\section{Pathology of optic nerve injury in mammals}

After optic nerve transection (avoiding retinal infarction), a cascade of inflammatory events is initiated, leading to degeneration of ganglion cell terminals and phagocytosis of somata in the retina. ${ }^{21-23}$ While a full review is beyond the scope of this article, it appears that the result of axotomy is to cause ganglion cells in the retina to undergo programmed cell death (apoptosis), such that only a small percentage remain after about 2 weeks. ${ }^{24}{ }^{25}$ The axotomised ganglion cells express molecular antigens that signal microglial cells in the retina to aid this organised process of self destruction. ${ }^{26}$ The apoptosis resulting from axotomy is therefore not dissimilar to the normal ontogenetic elimination of aberrant projections during the period of neuronal remodelling, ${ }^{27}$ when ganglion cell terminals projecting to incorrect targets cannot access appropriate growth factors at critical stages in development..$^{1328}$ One particular target derived growth factor, brain derived neurotrophic factor (BDNF) has been identified and cloned from the porcine superior colliculus. ${ }^{29}$ Not surprisingly, BDNF can also prevent ganglion cells from undergoing apoptosis if injected into the eye at the time of optic nerve lesion. ${ }^{30}{ }^{31}$ Peptides applied in vitro $^{32}$ and growth factors isolated from peripheral nerves (where regeneration is more successful than in the CNS) have also been shown to increase survival of lesioned ganglion cells, although their molecular structure is currently unknown. ${ }^{33}$ Some of these growth factors may also induce the expression of $\beta$ tubulin mRNA in ganglion cells, which has been shown to be important for axonal extension. ${ }^{35}$ This effect is probably independent of BDNF ${ }^{36}$ Indirectly, the axotomy related apoptosis can also be further reduced by the intraocular injection of molecules that directly inhibit the activity of microglia in the retina. ${ }^{37}$ The expression of the $b c l-2$ proto-oncogene also appears to be important for ganglion cell regeneration in vitro, although surprisingly this does not appear to be directly related to apoptosis. ${ }^{38}$

In conclusion, the normal programmed degeneration of ganglion cells that occurs after axotomy can now be interrupted in some cases with a variety of molecular methods (Fig 2A and B). If a ganglion cell can survive the effects of axotomy, one must now consider how this cell might re-extend an axon along the former pathway.

\section{Axon regrowth within the CNS environment}

It is well established that peripheral neurons can regenerate successfully over long distances within peripheral nerves. However, if a peripheral nerve is cut and the proximal end 

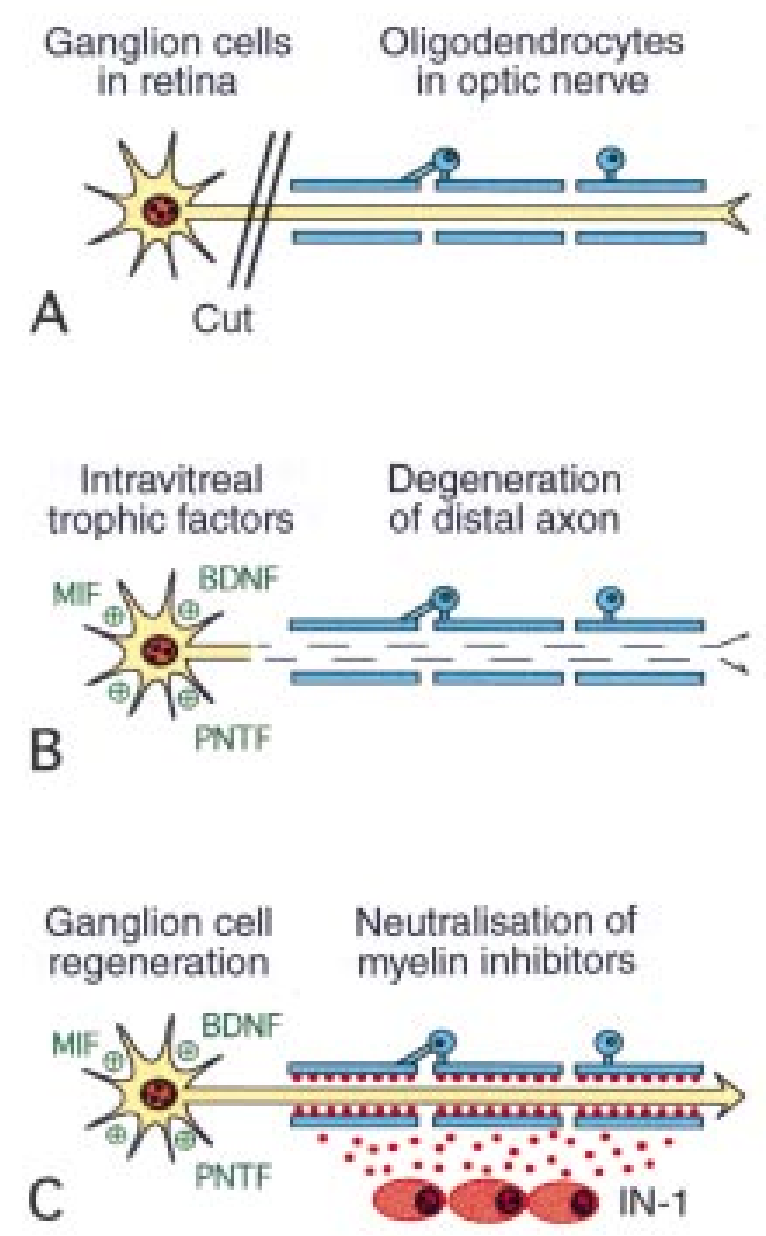

Figure 2 Optic nerve regeneration in mammals by the neutralisation of myelin associated inhibitory proteins. (A) Ganglion cell axons in the optic nerve are surrounded by oligodendrocytes which normally inhibit axon growth. (B) After axotomy, the distal axon will degenerate but the soma can be prevented from undergoing cell death by the intravitreal injection of certain growth factors and immunosuppressants. (C) In order to re-extend an axon along the optic nerve, the inhibitory myelin proteins in oligodendrocytes need to be neutralised. This can be done experimentally by the surgical implantation of hybridoma cells continually secreting monoclonal antibodies (IN-1) directed against and blocking the inhibitory proteins. The axon can then regenerate a significant distance along the optic nerve, although reconnection to central targets has not yet been achieved $(M I F=$ macrophage inhibitory factor; $B D N F=$ brain derived neurotrophic factor; PNTF = peripheral nerve trophic factors).

is turned back and implanted into the CNS, the peripheral neurons are only able to regenerate as far as the peripheral/ CNS junction and will not penetrate into the substance of the CNS. ${ }^{39}$ Conversely, some CNS neurons have been observed to have the capacity to regenerate into peripheral nerves when the latter are implanted into their central tracts. ${ }^{40}$ These observations led to Cajal's early conclusion that the failure of CNS regeneration was not due to an intrinsic inability for CNS neurons to regenerate, but was more the result of a CNS environment that totally inhibited any axonal growth within it. ${ }^{23}$ Cajal also noted that a transient sprouting of lesioned ganglion cells occurred before apoptosis in the mammalian retina. The sprouting axons were able to grow randomly a fair distance within the neural retina, but none could pass into the myelinated region of the optic nerve (Fig 3A). ${ }^{23}$ Further experiments have verified these early observations ${ }^{41}{ }^{42}$ and together with cell culture techniques, ${ }^{43}{ }^{44}$ have also confirmed that the myelin of oligodendrocytes is a princi- pal source of inhibitory molecules within the CNS environment.

\section{Inhibitory effects of oligodendrocytes}

In order for axons to regenerate within the myelinated regions of the CNS, these inhibitory proteins need somehow to be overcome or neutralised. Antibodies to the oligodendrocyte inhibitory proteins have been developed and successfully applied to the lesioned rat spinal cord. ${ }^{345} 46$ In the presence of hybridoma cells continually producing the monoclonal antibody "IN-1", a small proportion of lesioned spinal neurons are able to grow some distance along the spinal cord when supported by appropriate growth factors. ${ }^{47}$ These antibodies have also facilitated regeneration in the lesioned optic nerve, although the neutralising effect is reduced. Myelination in the optic nerve (Fig 3A) is very dense indeed when compared with the spinal cord, ${ }^{48}$ and the inhibitory effects of myelin proteins may therefore be much greater. Nevertheless, although not reconnecting to central targets, lesioned ganglion cells can regenerate considerable distances within the optic nerve in the presence of IN-1, when supported by BDNF in the retina (Fig 2C). ${ }^{2}$ It may be that future technical advances to allow greater penetration of antibody into the optic nerve and tracts will neutralise the entire pathway and allow ganglion cells access to central targets. Recently it has also been shown that ganglion cells may be able to regenerate along the myelinated optic nerve if driven by certain growth factors isolated from peripheral nerves. Theoretically at least, these growth factors may downregulate growth cone receptors for inhibitory molecules on regenerating ganglion cells, thus facilitating passage through myelinated tissues. ${ }^{34}$

\section{Inhibitory effects of astrocytes}

A second environmental factor that needs to be overcome is the inhibitory effect of gliosis. ${ }^{49}{ }^{50}$ Gliosis is the scar reaction around a site of CNS injury, mediated mainly by the proliferation of astrocytes. ${ }^{51}$ The astrocytes form a dense plug of gliotic tissue in an attempt to wall off the CNS from pathogens and re-establish the blood-brain barrier. ${ }^{52}$ Gliosis inhibits axon regeneration directly by presenting a physical barrier to regrowing axons, and also indirectly by the synthesis of inhibitory molecules. ${ }^{53}$ One particular inhibitory molecule that has been characterised in detail is chondroitin sulphate proteoglycan (CSPG).$^{54}$ This molecule is also expressed during development where it has a putative role in axon guidance by forming barriers to direct growth cones. ${ }^{55-57}$ Quite why CSPG is also expressed within a glial scar is uncertain, and direct neutralisation with antibodies (as with myelin) has not yet been achieved in vivo. In contrast with myelin, however, gliosis is only present around the site of injury, and regrowing axons can in some cases simply detour around the glial scar to grow within undisrupted CNS tissue. ${ }^{58} 59$

Within the retina, the inhibitory effects of gliosis may not be as marked as elsewhere in the CNS. ${ }^{60}$ Astrocytes migrate into the retina through the optic nerve head at early stages of development (Fig 3B), but remain only very sparsely populated within the nerve fibre layer (Fig 3C). ${ }^{6162}$ The gliotic reaction to retinal injury is minimal and resulting CSPG expression is barely detectable. ${ }^{60}$ This may partly explain why ganglion cells regenerate readily into peripheral nerve transplants when the latter are implanted into the retina in the presence of appropriate growth factors. This may be an important finding when considering the possibility of using peripheral nerve bridges to bypass the myelinated optic nerve and lead regenerating axons into central targets (see below). 

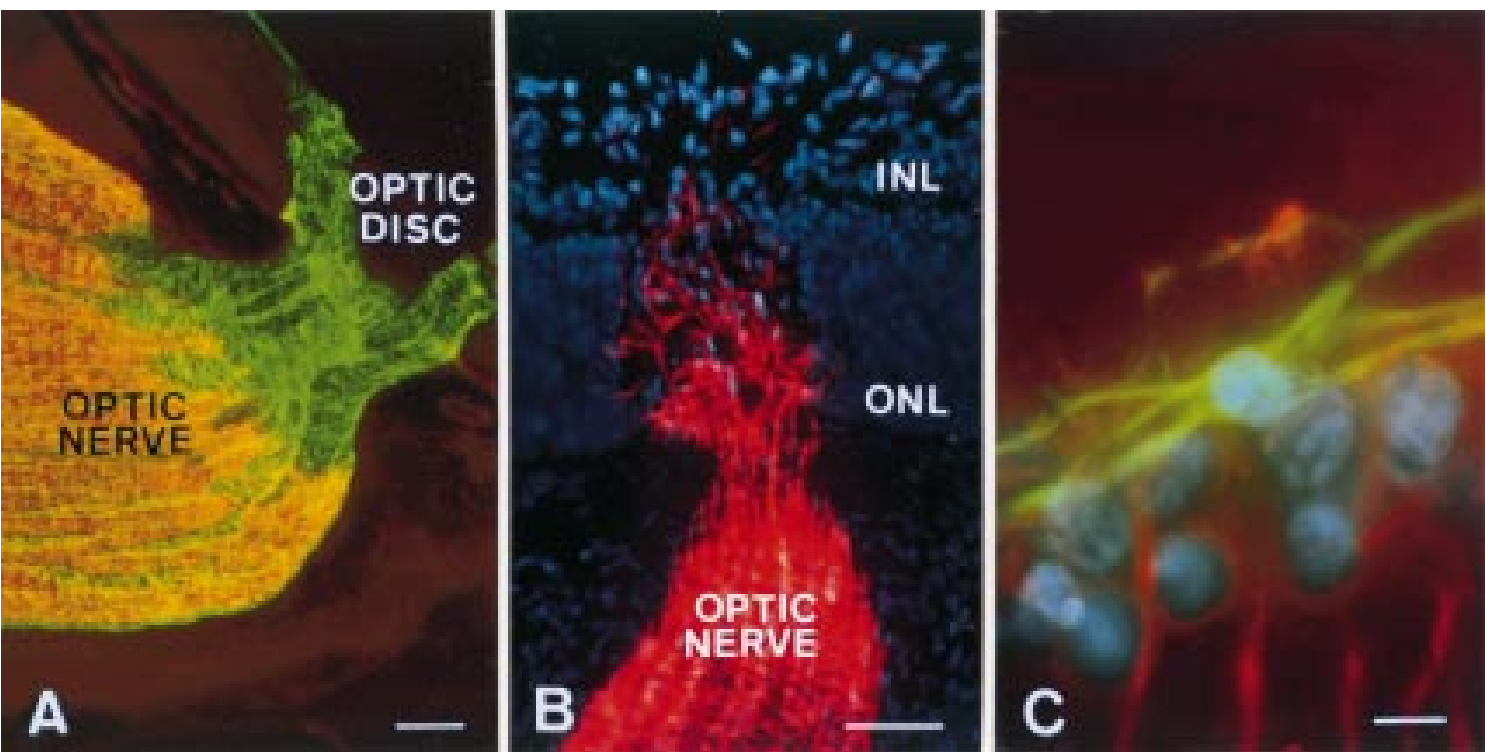

Figure 3 Glial cells within the visual system. (A) The optic nerve is densely myelinated (orange) and is thus inhibitory to axonal growth, although the optic nerve head and adjacent retina contain only astrocytes (green) and are therefore preferred regions for the insertion of peripheral nerve grafts.

(B) Astrocytes (red) migrate into the retina through the optic nerve head at early stages of development (INL = inner neuroblastic layer; ONL = outer neuroblastic layer) to surround retinal blood vessels. (C) A mature astrocyte (green) shown close to the ganglion cell layer (blue nuclei) and perpendicular to the radial processes of Müller cells (red). After CNS injury, astrocytes normally express inhibitory proteins to block regeneration, but this has not been observed in the retina. Glial cell differences may therefore explain why the retina is probably a more favourable site for regeneration than elsewhere in the CNS. Scale bars: $A=50 \mu \mathrm{m} ; B=25 \mu \mathrm{m} ; C=10 \mu \mathrm{m}$ (opossum)

\section{Peripheral nerve transplants}

Since the CNS environment contains molecules inhibitory to axonal growth, an alternative to antibody mediated neutralisation of these inhibitory molecules is to simply bypass the CNS tract altogether with a bridge fashioned from a peripheral nerve (Fig 4). ${ }^{63}$ Experimentally the graft is typically sciatic nerve, connected proximally to viable neurons at the site of lesion, and distally to the relevant CNS target region. Growth factors are also applied to the lesioned neurons to augment axonal regrowth. Initial results suggest that multiple grafts across descending projections in the lesioned spinal cord have been successful in returning locomotion to paraplegic rats. ${ }^{5}$ Regeneration occurs naturally within peripheral nerves and there is also evidence of as yet undefined growth factors originating from within the substance of the grafts. ${ }^{33} 34$

In the visual system, regeneration through peripheral nerve grafts has been of equal success. ${ }^{64}{ }^{65}$ Typically, the optic nerve is lesioned close to the optic nerve head but avoiding damage to the central retinal artery (Fig 4A). A peripheral nerve can then be connected either to the optic nerve head or directly into the retina. With appropriate intravitreal growth factors ${ }^{22}$ and as yet undefined growth factors diffusing from the peripheral nerve, ${ }^{33}{ }^{34}$ ganglion cells survive the effects of axotomy and re-extend axons into the graft (Fig 4B). If the distal end of the graft is connected to central visual relays, functional reconnections can be made. ${ }^{66-68} \mathrm{~A}$ most remarkable example of this is the return of the light pupil constriction reflex when the graft is connected to the pretectal nucleus in rats (Fig 4C) ${ }^{69}$ The return of visually evoked behavioural responses in rodents after grafting also implies functional connection with higher visual centres. ${ }^{64}{ }^{65}$ Similar experiments have shown that regeneration is also possible distally in the retinotectal projection; through peripheral nerve grafts placed across lesions of the optic tracts. ${ }^{70}$

The nerve grafting experiments are very encouraging because they demonstrate unequivocally that lesioned retinal ganglion cells are able to regenerate and reform functional connections. It should be remembered, however, that most of these experiments have been conducted in the visual system of rodents, and that recovery has been defined as the return of a reflex or visually evoked potentials in the tectum. Although there is some indirect evidence that optic nerve regeneration may also contribute to visual perception, from recent behavioural studies into the capacity for optic nerve grafted rats to discriminate between horizontal and vertical patterns. ${ }^{65}$ In reality, extrapolation of these findings into the human visual system is very speculative, mainly because of our dependence on the retinogeniculate projection. The geniculate input of this projection is precisely retinotopically ordered, ${ }^{13}$ and one must assume that this would also have to be re-established after regeneration for any meaningful return of visual function. The success of peripheral nerve grafts still needs to be assessed in primates, with particular emphasis on examining the potential for re-establishment of retinotopic order within a regenerating retinogeniculate projection.

\section{Embryonic CNS transplants}

The transplantation of human fetal striatal grafts is now an established clinical procedure in the treatment of Parkinson's disease. ${ }^{71}$ Laboratory experiments have confirmed that dopaminergic neurons transplanted from fetal substantia nigra are able to reform functional connections with host brain targets some distance away. ${ }^{72}$ The significance of this achievement should not be underestimated when considering therapeutic possibilities for optic nerve and spinal cord repair.

There are several reasons why embryonic tissue transplants are successful. Firstly, the neurons are in an active growth phase and advance readily into host brain without dependence on externally administered growth factors. ${ }^{73}$ Secondly, it seems that the growth cones of embryonic neurons are not inhibited by myelin proteins in the same way as regenerating adult neurons. Thus embryonic neurons can grow and re-establish connections along myelinated pathways of the host brain without the need for exogenously introduced myelin inhibitors. ${ }^{59}$ Thirdly, there is evidence that the gliosis around an embryonic transplant is much reduced when compared with disrupted adult tissue, and does not act as a barrier to growing 

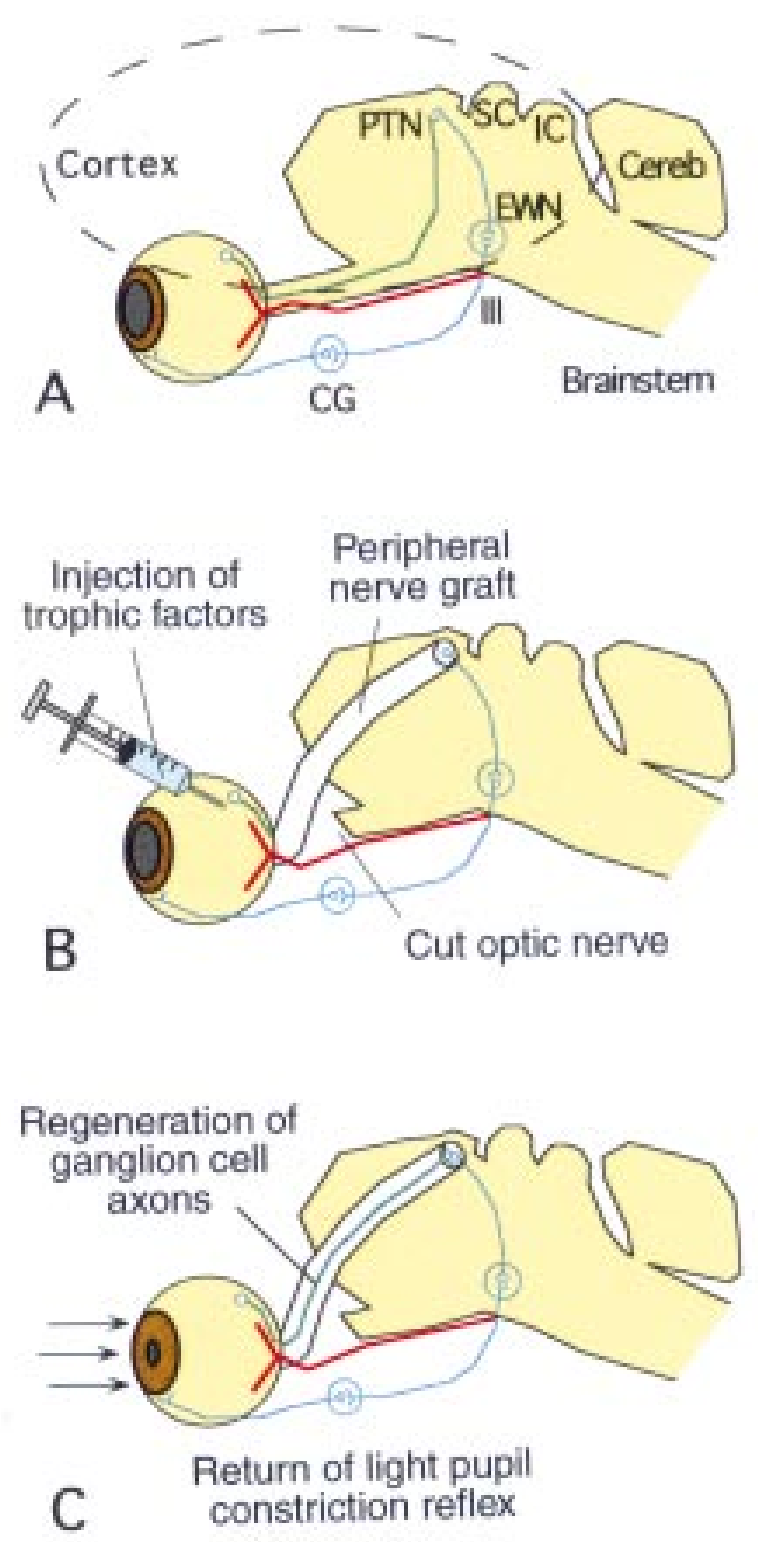

Figure 4 Utilisation of a peripheral nerve graft to connect regenerating ganglion cells directly to central targets. (A) The normal light reflex is mediated by ganglion cells through synapses in the pretectal nucleus (PTN), Edinger-Westphal nucleus (EWN), and ciliary ganglion (CG) of the oculomotor nerve (III). The positions of the superior and inferior colliculi (SC and IC) and cerebellum (Cereb) are also shown. (B) After optic nerve transection, intravitreal growth factors can sustain the lesioned ganglion cells in the retina, provided that the retinal blood supply remains viable (shown in red). A peripheral nerve transplant can provide a conduit between the optic nerve head and pretectal nucleus. (C) Ganglion cell axons are able to regenerate within the favourable environment of the peripheral nerve graft to reform functional connections in the pretectal nucleus and restore the light reflex. The graft thus facilitates regeneration by bypassing the inhibitory CNS environment altogether.

neurons ${ }^{875}$ Finally, the neurons growing out of the embryonic tissue may possess some navigational properties that direct them to appropriate targets some distance away in the host brain. ${ }^{76}$

Intraspinal embryonic transplants have also been successful in facilitating repair of the lesioned spinal cord in neonatal rats. ${ }^{7}$ It should be remembered, however, that functional repair of the adult spinal cord requires regeneration of corticospinal connections from existing
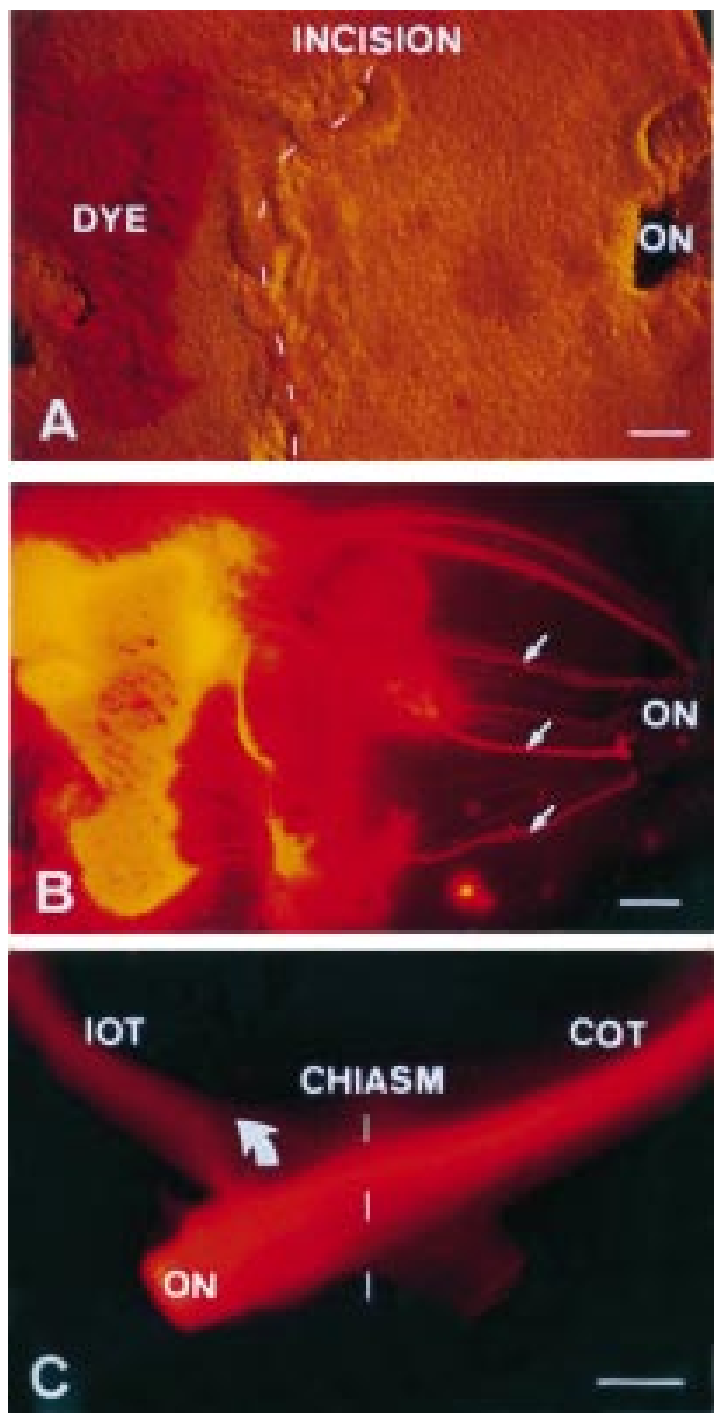

Figure 5 Navigation of regenerating ganglion cells in the developing mammalian CNS. (A) At early stages of development, ganglion cells can regenerate across an incision made in the retina. The optic nerve (ON) is shown to the right and an axon labelling dye is shown embedded in the temporal retina to the left. (B) Under fluorescent light, the precise path of regenerating axons can be seen. Some axons have regrown directly across the incision (arrows) and all are appropriately guided into the optic nerve. (C) At the chiasm, axons originating from the temporal retina turn appropriately (arrow) to enter the ipsilateral optic tract (IOT), while the remainder project to the contralateral optic tract (COT). This study not only demonstrates that mammalian ganglion cells can regenerate at early stages of development, but more importantly, also have a capacity for navigation back to appropriate targets. Scale bars: $A=100 \mu \mathrm{m} ; B=100$ $\mu \mathrm{m} ; \mathrm{C}=250 \mu \mathrm{m}$ (opossum)

motor neurons in the cortex. Embryonic neurons emanating from the intraspinal graft may make local connections but are unlikely to exert controlling influences in the same way as neurons from higher motor areas. Functional reconnections would have to come from existing lesioned neurons, and these neurons are still unable to regenerate across fetal grafts placed at the site of spinal cord injury. ${ }^{77}$ For similar reasons, it follows that embryonic grafts are unlikely to facilitate repair of existing ganglion cells simply by being placed at a site of interruption of the visual pathway. Transplantation of the whole embryonic retina is required, totally substituting the damaged host retinofugal projection.

Transplants of embryonic retinal tissue are successful when placed directly onto host tectum, and can even reform functional connections with host target neurons. The synaptic connections made in congenitally blind mice 
are very similar to normal, also suggesting that the ability of a retinal transplant to innervate a host brain seems not to depend on prior innervation of visual targets. ${ }^{6}$ The main drawback of retinal transplants, however, is that they consist of only neural tissue, and cannot therefore confer the optical properties of a whole eye. Interestingly, photoreceptors within the transplant are able to recruit local macrophages to take on a role similar to pigment epithelium, ${ }^{78}$ and visual function is sufficient at least to restore the light pupil constriction reflex $^{79}$ and certain behavioural responses. ${ }^{80}$ There does not appear to be a retinotopic projection to host targets, ${ }^{81}$ but in any case, this is probably irrelevant in the absence of any optical system to project a visuotopic image onto the graft itself. In reality, therefore, although the regeneration characteristics of retinal transplants are good, for functional return of vision, grafts would most likely need to be sited within the host eye. The subsequent requirement for regeneration over long distances through a host or transplanted optic nerve, and the uncertainty of retinotopy in axons arriving at host targets needs then to be considered. ${ }^{82} \mathrm{~A}$ clinical therapy using retinal grafts to restore vision, while theoretically possible, would therefore be considerably more complicated than currently successful transplantation strategies to treat extrapyramidal disorders.

\section{Regeneration of retinotopic maps}

In all the above paradigms of mammalian optic nerve regeneration, the question of specificity (recreation of visual maps) remains unanswered. The lower vertebrate experiments described at the beginning of this review demonstrate the dependence of visual function on the restoration of retinotopic maps in the regenerating projection. It is highly likely that functional return of vision in humans would also require successful navigation of regenerating ganglion cells to appropriate targets in the lateral geniculate nucleus. In this respect, the requirements for optic nerve regeneration are far more stringent than in the spinal cord. Precise surgical reconnection of regenerating axons to individual geniculate targets is clearly an improbability considering the vast number of axons within the optic nerve. Instead we must hope that, as in the lower vertebrate model, some capacity to replicate the normal processes of development might exist in adulthood to guide regenerating axons back to their targets or remodel aberrant projections. In vitro observations of the regenerating connections between rodent retinal and tectal explants have suggested that some guidance molecules can be re-expressed in the adult. ${ }^{83}$ Similarly, our recent observations in the regenerating retinofugal projection of the opossum have shown at early stages that regeneration of ganglion cells is possible along the normal visual pathway (Fig 5A and $\mathrm{B}$ ), and that regenerating axons respond to appropriate guidance cues within the optic chiasm (Fig 5C).$^{85}$ Quite how these guidance cues might persist or be re-expressed to guide regeneration in the adult visual pathway remains the critical issue.

\section{Summary}

Three separate experimental models of optic nerve regeneration have been presented-along the existing pathway in the presence of antibodies to neutralise inhibitory molecules, along peripheral nerve grafts and from retinal transplants. Each offers a theoretical clinical strategy for restoration of vision, if the mechanism of re-establishment of maps and reconnection to appropriate targets during regeneration can be determined. This is the process of axon guidance, and underlines the importance of our research into the molecular determinants that guide normal development of the visual system.
Some of the experiments described in this review were funded by the Medical Research Council at the University of Oxford, with additional support from the Wellcome Trust. Jeremy Taylor kindly provided the photograph for Figure 1C. I am grateful to Kwok-Fai So and Anson Cho for teaching me peroneal to optic nerve transplantation.

ROBERT E MACLAREN

Division of Ophthalmology, Royal Berkshire Hospital,

Reading RG1 5AN

Shatz CJ, O'Leary DM. Repair and replacement to restore sight. Arch Ophthalmol 1993;111:472-7.

2 Wiebel D, Cadelli D, Schwab ME. Regeneration of lesioned rat optic nerve fibers is improved after neutralization of myelin-associated growth inhibitors. Brain Res 1994;642:259-66.

3 Schnell L, Schwab ME. Axonal regeneration in the rat spinal cord produced by an antibody against myelin-associated neurite growth inhibitors. Nature 1990;343:269-72.

4 So KF, Aguayo AJ. Lengthy regrowth of cut axons from ganglion cells after peripheral nerve transplantation into the retina of adult rats. Brain Res 1985;328:349-54.

5 Cheng H, Cao Y, Olson L. Spinal cord repair in adult paraplegic rats: partial restoration of hind limb function. Science 1996;273:510-13.

6. Horsburgh GM, Lund RD, Hankin MH. Retinal transplants in congenitally blind mice: patterns of projection and synaptic connectivity. 7 Comp Neurol 1993;327:323-40.

7 Iwashita Y, Kawaguchi S, Murata M. Restoration of function by replacement of spinal cord segments in the rat. Nature 1994;367:167-70.

8 MacLaren RE, Taylor JSH. A critical period for axon regrowth through a lesion in the developing mammalian retina. Eur f Neurosci 1995;10:211118.

9 MacLaren RE. Myelination in the opossum optic nerve: late appearance of inhibitors implicates an earlier non-myelin factor in preventing ganglion cell regeneration. F Comp Neurol 1996;372:27-36.

10 Nicholls JG, Saunders NR. Regeneration of immature mammalian spinal cord after injury. Trends Neurosci 1996;19:229-34.

11 Sperry RW. Optic nerve regeneration with return of vision in anurans. $\mathcal{F}$ Neurophysiol 1944;7:57-69.

12 Taylor JSH, Jack JL, Easter SS. Is the capacity for optic nerve regeneration related to continued retinal ganglion cell production in the frog? Eur $\mathcal{F} \mathrm{Neu-}$ rosci 1989;1:626-38.

13 Guillery RW. Development of the pathways from the eye to the optic tract. In: Lam DM, Shatz CJ, eds. Development of the visual system. Boston, MA: MIT Press, 1991:153-71.

14 Lyon MJ, Stelzner DJ. Tests of the regenerative capacity of tectal efferent axons in the frog, Rana pipiens. F Comp Neurol 1987;255:511-25.

15 Sperry RW. Visuomotor coordination in the newt (Triturus viridescens) after regeneration of the optic nerve. 7 Comp Neurol 1943;79:33-55.

16 Fujisawa $\mathrm{H}$, Tani N, Watanabe $\mathrm{K}$, et al. Branching of regenerating retinal axons and preferential selection of appropriate branches for specific neuronal connection in the newt. Dev Biol 1982;90:43-57.

17 Constantine-Paton M, Law MI. Eye-specific termination bands in tecta of three-eyed frogs. Science 1978;202:639-41.

18 Law MI, Constantine-Paton M. Anatomy and physiology of experimentally produced striped tecta. $\mathcal{F}$ Neurosci 1981;1:741-59.

19 Kaprielian Z, Patterson PH. The molecular basis of retinotectal topography. BioEssays 1993;16:1-11.

20 Marotte LR, Mark RF. Retinal projections to the superior colliculus and dorsal lateral geniculate nucleus in the Tammar wallaby (Macropus eugenii): II Topography after rotation of an eye prior to retinal innervation of the brain. F Comp Neurol 1988;271:274-92.

21 Richardson PM, Issa VMK, Shemie S. Regeneration and retrograde degeneration of axons in the rat optic nerve. F Neurocytol 1982;11:949-66.

22 Thanos S, Thiel H. Mechanisms governing neuronal degeneration and axonal regeneration in the mature retinofugal system. $\mathcal{F}$ Cell $\mathrm{Sci}$ 1991;15:125-34.

23 Cajal SR. Traumatic degeneration and regeneration of the optic nerve and retina. In: May R, ed. Degeneration and regeneration of the nervous system. Vol 2. New York: Hafner, 1928:583-96.

24 Berkelaar M, Clarke DB, Wang YC, et al. Axotomy results in delayed death and apoptosis of retinal ganglion cells in adult rats. $f$ Neurosci 1994;14:4368-74.

25 Garcia-Valenzuela E, Gorczyca W, Darzynkiewicz Z, et al. Apoptosis in adult retinal ganglion cells after axotomy. $\mathcal{F}$ Neurobiol 1994;25:431-8.

26 Thanos S. The relationship of microglial cells to dying neurons during natural neuronal cell death and axotomy-induced degeneration of the rat retina. Eur $\mathcal{F}$ Neurosci 1991;3:1189-207.

27 Lang RA, Bishop JM. Macrophages are required for cell death and tissue remodelling in the developing mouse eye. Cell 1993;74:453-62.

28 Vanselow J, Dütting D, Thanos T. Target dependence of chick retinal ganglion cells during embryogenesis: cell survival and dendritic development. glion cells during embryogenesis:

29 Leibrock J, Lottspeich F, Hohn A, et al. Molecular cloning and expression of brain-derived neurotrophic factor. Nature 1989;341:149-52.

30 Thanos S, Bähr M, Barde YA, et al. Survival and axonal elongation of adult rat retinal ganglion cells: in vitro effects of lesioned sciatic nerve and brain derived neurotrophic factor. Eur F Neurosci 1989;1:19-26.

31 Wiebel D, Kreutzberg GW, Schwab ME. Brain-derived neurotrophic factor (BDNF) prevents lesion-induced axonal die-back in young rat optic nerve. Brain Res 1995;679:249-54

32 Meyerfranke A, Kaplan MR, Pfrieger FW, et al. Characterization of the signalling interactions that promote the survival and growth of developing retinal ganglion cells in culture. Neuron 1995;15:805-19.

33 Cho EYP, So KF. Characterization of the sprouting response of axon-like processes from retinal ganglion cells after axotomy in adult hamsters: a model using intravitreal implantation of a peripheral nerve. 7 Neurocytol 1992;21:589-603.

34 Berry M, Carlile J, Hunter A. Peripheral nerve explants grafted into the vitreous body of the eye promote the regeneration of retinal ganglion cell axons severed in the optic nerve. $\mathcal{F}$ Neurocytol 1996:25:147-70.

35 McKerracher L, Essagian C, Aguayo AJ. Marked increase in beta-tubulin messenger RNA expression during regeneration of axotomized retinal ganglion cells in adult mammals. $\mathcal{F}$ Neurosci 1993;13:5294-300. 
36 Fournier AE, McKerracher L. Expression of specific tubulin isotypes increases during regeneration of injured CNS neurons, but not after the application of

37 Thanos S, Mey J, Wild M. Treatment of the adult retina with microglia-suppressing factors retards axotomy-induced neuronal degradation and enhances axonal regeneration in vivo and in vitro. $\mathcal{F}$ Neurosci 1993 ; 13:455-66.

38 Chen DF, Schneider GE, Martinou JC, et al. Bcl-2 promotes regeneration of severed axons in mammalian CNS. Nature 1997;385:434-9.

39 Windle WF. Regeneration of axons in the vertebrate central nervous system. Physiol Rev 1956;36:426-40.

40 Tello F. La influencia del neurotropismo en la regeneraçion de los centros nerviosos. Trab Lab Invest Biol 1911;9:124-59.

41 McConnell P, Berry M. Regeneration of retinal ganglion cells in the adult mouse retina. Brain Res 1982;241:362-5.

42 Schwab ME, Thoenen H. Dissociated neurons regenerate into sciatic but not optic nerve explants in culture irrespective of neurotrophic factors. $\mathcal{F}$ not optic nerve explants in
Neurosci $1985 ; 5: 2415-23$.

43 Caroni P, Schwab ME. Two membrane protein fractions from rat central myelin with inhibitory properties for neurite growth and fibroblast spreading. $₹$ Cell Biol 1988;106:1281-8.

44 Fawcett JW, Rokos J, Bakst I. Oligodendrocytes repel axons and cause growth cone collapse. F Cell Sci 1989;92:93-100

45 Savio T, Schwab ME. Rat CNS white matter, but not gray matter, is nonpermissive for neuronal cell adhesion and fiber outgrowth. 7 Neurosci 1989;9:1126-33.

46 Mukhopadhyay G, Doherty P, Walsh FS, et al. A novel role for myelin-associated glycoprotein as an inhibitor of axonal regeneration. Neuron 1994;13:757-67.

47 Schnell L, Schneider R, Kolbeck R, et al. Neurotrophin-3 enhances sprouting of corticospinal tract during development and after adult spinal cord lesion. Nature 1994;367:170-3.

48 Hildebrand C, Remahl S, Persson H, et al. Myelinated nerve fibres in the CNS. Prog Neurobiol 1993;40:319-84.

49 Johnson AR. Contact inhibition in the failure of mammalian CNS axonal regeneration. BioEssays 1993;15:807-13.

50 Windle WF, Clemente CD, Chambers WW. Inhibition of formation of a glial barrier as a means of permitting a peripheral nerve to grow into the glial barrier as a means of permitting
brain. f Comp Neurol 1952;96:359-69.

51 Lefrançois T, Fages C, Peschanski M, et al. Neuritic outgrowth associated with astroglial phenotypic changes induced by antisense glial fibrillary acidic protein (GFAP) mRNA in injured neuron-astrocyte cocultures. $\mathscr{F}$ Neurosci 1997; 17:4121-8.

52 Mansour H, Asher R, Dahl D, et al. Permissive and non-permissive reactive astrocytes: immunofluorescence study with antibodies to the glial hyaluronate-binding protein. $\mathcal{F}$ Neurosci Res 1990;25:300-11

53 Canning DR, Hoke A, Malemud CJ, et al. A potent inhibitor of neurite outgrowth that predominates in the extracellular matrix of reactive astrocytes. Int $\mathcal{F}$ Dev Neurosci 1996;14:153-75.

54 Snow DM, Lemmon V, Carrino DA, et al Sulfated proteoglycans in astroglial barriers inhibit neurite outgrowth in vitro. Exp Neurol 1990;109: 111-30

55 Snow DM, Watanabe M, Letourneau PC, et al. A chondroitin sulfate proteoglycan may influence the direction of retinal ganglion cell outgrowth. Development 1991;113:1473-85.

56 McAdams BD, McLoon SC. Expression of chondroitin sulfate and keratan sulfate proteoglycans in the path of growing retinal axons in the developing chick. F Comp Neurol 1995;352:594-606.

57 Brittis PA, Silver J. Multiple factors govern intraretinal axon guidance: a time lapse study. Mol Cell Neurosci 1995;6:413-32.

58 Goldberg S, Frank B. Will central nervous systems in the adult mammal regenerate after bypassing a lesion? A study in the mouse and chick visual systems. Exp Neurol 1980;70:675-89

59 MacLaren RE, Taylor JSH. Regeneration in the developing optic nerve: correlating observations in the opossum to other mammalian systems. Prog Neurobiol 1997;53:381-98.

60 MacLaren RE. Development and role of retinal glia in regeneration of ganglion cells following retinal injury. Br f Ophthalmol 1996;80:458-64.
61 Ling T, Mitrofanis J, Stone J. Origin of retinal astrocytes in the rat: evidence of migration from the optic nerve. 7 Comp Neurol 1989;286:345-52.

62 Distler C, Wiegel H, Hefmann KP Glia cells of the monk. retina. I Astrocytes. F Comp Neurol 1993;333:134-47.

63 David S, Aguayo AJ. Axonal elongation into peripheral nervous system "bridges" after central nervous system injury in adult rats. Science 1981;214:931-3.

64 Sasaki H, Coffrey P, Villegas-Perez MP, et al. Light-induced EEG desynchronization and behavioural arousal in rats with restored retinocollicular projection by peripheral nerve graft. Neurosci Lett 1996;218:45-8.

65 Thanos S, Naskar R, Heiduschka P. Regenerating ganglion cell axons in the adult rat establish retinofugal topography and restore visual function. Exp Brain Res 1997;114:483-91.

66 Carter DA, Bray GM, Aguayo AJ. Regenerated retinal ganglion cell axons can form well-differentiated synapses in the superior colliculus of adult hamsters. F Neurosci 1989;9:4042-50.

67 Kierstead SA, Rasminsky M, Fukuda Y, et al. Electrophysiological responses in hamster superior colliculus evoked by regenerating retinal axons. Science 1989;246:255-7.

68 Carter DA, Bray GM, Aguayo AJ. Long-term growth and remodeling of regenerated retino-collicular connections in adult hamsters. $f$ Neurosci 1994;14:590-8.

69 Thanos S. Adult retinofugal axons regenerating through peripheral nerve grafts can restore the light-induced pupilloconstriction reflex. Eur $\mathcal{F}$ Neurosci 1992;4:691-9.

70 Sawai H, Sugioka M, Morigiwa K, et al. Functional and morphological restoration of intracranial brachial lesion of the retinocollicular pathway by peripheral nerve autografts in adult hamsters. Exp Neurol 1996;137:94104 .

71 Olanow CW, Kordower JH, Freeman TB. Fetal nigral transplantation as a therapy for Parkinson's disease. Trends Neurosci 1996;19:102-9.

72 Wictorin K, Clarke DJ, Bolam JP, et al. Fetal striatal neurons grafted into the ibotenate lesioned adult striatum:efferent projections and synaptic contacts in the host globus pallidus. Neuroscience 1990;37:301-15.

73 Clowry G, Katarzyna S, Vrbová G. Transplants of embryonic motoneurones to adult spinal cord: survival and innervation abilities. Trends Neurosci 1991;14:355-7.

74 Wictorin K, Brundin P, Gustavii B, et al. Reformation of long axon pathways in adult rat central nervous system by human forebrain neuroblasts. Nature 1990;347:556-8.

75 Bregman BS. Spinal cord transplants permit the growth of serotonergic axons across the site of neonatal spinal cord transection. Dev Brain Res 1987;34:265-79.

76 Davies SJA, Field PM, Raisman G. Long fibre growth by axons of embryonic mouse hippocampal neurons microtransplanted into the adult rat fimbria. Eur $\mathcal{F}$ Neurosci 1993;5:95-106.

77 Schnell L, Schwab ME. Sprouting and regeneration of lesioned corticospinal tract fibres in the adult rat spinal cord. Eur 7 Neurosci 1993;5:1156-71.

78 Banerjee R, Lund RD. A role for microglia in the maintenance of photoreceptors in retinal transplants lacking pigment epithelium. I Neurocytol 1992;21:235-43

79 Klassen H, Lund RD. Retinal graft-mediated pupillary responses in rats: restoration of a reflex function in the mature mammalian brain. 7 Neurosi 1990;10:578-87.

80 Lund RD, Radel JD, Coffrey PJ. The impact of intracerebral retinal transplants on types of behavior exhibited by host rats. Trends Neurosci 1991;14:358-62.

81 Galli L, Rao K, Lund RD. Transplanted rat retinae do not project in a topographic fashion on the host tectum. Exp Brain Res 1989;74:427-30.

82 Lund RD, Radel JD, Hankin $\mathrm{MH}$, et al. Intracerebral retinal transplants. In: Lam DMK, Bray GM, eds. Regeneration and plasticity in the visual system. Cambridge, MA: MIT Press, 1992:125-46.

$83 \mathrm{Bähr}$ M, Bonhoeffer F. Perspectives on axonal regeneration in the mammalian CNS. Trends Neurosci 1994;17:473-9.

84 Wizenmann A, Thies E, Klostermann S, et al. Appearance of target-specific guidance information for regenerating axons after CNS lesions. Neuron 1993;11:975-83.

85 MacLaren RE, Taylor JSH. Chiasmatic specificity in the regenerating mammalian optic nerve. Exp Neurol 1997;147:279-86. 